\title{
Violencia y control social: la lógica de la culpabilidad en un grupo indígena
}

\author{
Víctor M. Franco Pellotier
}

A partir del examen de la lógica de la violencia ejercida en un grupo indígena, el autor centra su análisis en los mecanismos socioculturales que los actores sociales emplean para comprender y controlar su participación colectiva en las cadenas de venganza de sangre. Esta lógica basada en el pensamiento mágico sobre las creencias de nagualismo - estudiadas desde hace décadas entre los grupos indígenas - permite comprender las restricciones que este tipo de sociedades ha creado como formas de control social de homicidios, que se suceden cíclicamente en la vida comunitaria. En una delgada frontera que asocia los actos de violencia física y aquellas acciones imputadas al nagualismo causantes de muertes, la comunidad establece un tiempo de espera, en el que observa el comportamiento de los sospechosos, deduciendo y atribuyendo la culpabilidad de los hechos violentos. Si bien este mecanismo no se considera probatorio en términos judiciales, la fuerza de la creencia produce la certeza de que los culpables serán descubiertos tarde o temprano y con ello se produce la restricción e inhibición de tales hechos.

Examining the logics of violence in an indigenous group, the author focuses on the socio cultural mechanisms used by the social agents to understand and control their collective participation in the vendettas. These logics, based on magical thought and belief in nahualism - described in indigenous groups decades ago- allows us to understand the constrictions these societies created as a form of social control of murders, that ciclacally occur in the life of community. On a thin frontier associating acts of physical violence and actions attributed to nahualism, resulting in human deaths, the community prescribes a waiting period, within which the behavior of suspected persons is observed, until the responsability for the violent deeds is deduced and assigned. Though this mechanism is not considered as a legal proof, the belief is so strong that it is assumed that sooner or later whoever is guilty will be discovered, and that belief limits and inhibits such deeds.

VíCtOR M. FRANCO PELLOTIER: CIESAS-México. 
$\mathrm{E}$ 1 propósito de este ensayo es destacar la importancia del estudio de la violencia en relación con los sistemas culturales; subraya, en especial, la red de relaciones sociales establecidas en un grupo indígena en torno a los modos de venganza, donde el resultado es el homicidio en el contexto de prácticas culturales mágico-simbólicas, vinculadas principalmente al nagualismo.

Desde hace varios decenios, el tema del nagualismo ha sido estudiado por diversos autores, cada uno con énfasis en diversos aspectos. En general se le comprende como un conjunto de creencias, de raíces mesoamericanas, que fundamentalmente consiste en el desdoblamiento de una persona en un animal o fuerza de la naturaleza. También se han abordado como un tema central las conexiones entre el nagualismo y las prácticas de control social.

$\mathrm{Al}$ respecto son de especial interés para este ensayo los trabajos de Alfonso Villa Rojas sobre nagualismo y sistemas de parentesco (1947) y sobre el control social de las relaciones interpersonales comunitarias (1963). Destacan también los estudios de Aguirre Beltrán $(1958,1963)$, Holland (1963) y Foster (1965).
Llama la atención la vigencia de las creencias sobre el nagualismo y su aplicación a condiciones sociales actuales, a pesar de tratarse de prácticas culturales que han ido desapareciendo en las sociedades indígenas.

El caso de estudio corresponde a la zona habitada por el grupo indígena amuzgo en Oaxaca, en la región conocida como Costa Chica, y fue registrado a partir de 1993, aunque mucha de la información data de fechas anteriores y posteriores. La Costa Chica es una amplia región interétnica que ha sido caracterizada como zona de alta incidencia de hechos violentos, no sólo en conflictos agudos, sino en la vida cotidiana. La investigación que Veronique Flanet realizó en la década de 1970 y publicó en su libro Viviré si Dios quiere (1989) muestra con claridad el contexto regional de la violencia. Sin embargo, junto a la situación general existen también formas propias de ejercer y controlar la violencia al interior de los grupos indígenas. El caso estudiado no se caracteriza por un muy alto indíce de homicidios; no es la cantidad de actos violentos lo que llama la atención, sino la presencia de la venganza y el homicidio en la vida social de los individuos.

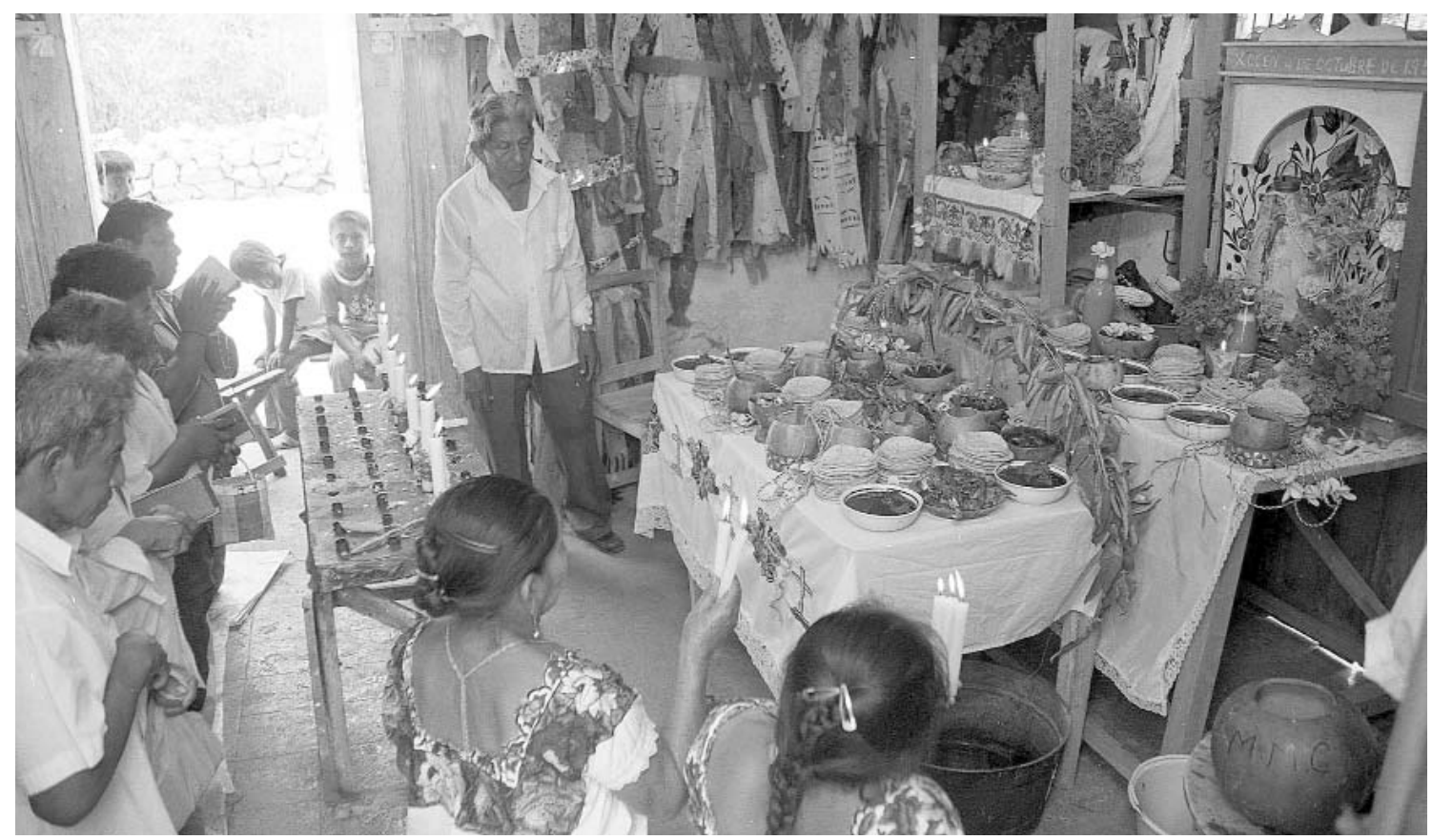

Celebración del santo patrón. Durante los rezos los seres sobrenaturales saborean la "esencia" de la comida / Christian Rasmussen. 
Hay una diversidad de causas que influyen, en un momento dado, en las manifestaciones de este tipo de violencia. La relación entre los homicidios, las venganzas y las características mágico-culturales vinculadas al nagualismo, al mismo tiempo que parece ser un mecanismo generador de violencia puede ser comprendido como un sistema de control social que limita, controla y restringe los hechos violentos.

En un lapso de aproximadamente año y medio se produjo en un poblado de la zona una serie de homicidios (entre 12 y 18). La mayoría no llegó a aclararse, lo que propició un clima de intranquilidad. Sobre esos hechos se llegaron a escuchar comentarios entre vecinos, en los caminos, en las cantinas, en domicilios particulares y hasta en la iglesia; al parecer, toda la sociedad local seguía con inquietud los acontecimientos. Luego, en el transcurso de dos o tres meses, parecía que uno se encontrase en otro lugar, en otro pueblo y con otra gente: no se escuchaban más comentarios; en apariencia no había más información sobre los homicidios, y habían vuelto la tranquilidad y la confianza al lugar, tal vez debido al cambio de autoridades locales.

Esta alternancia entre tiempos de violencia y de paz es parte del largo proceso de una conflictividad latente; tal carácter cíclico fue considerado por Flanet (1989) como una señal profunda que penetra en las raíces de la violencia en la región de la costa. El tiempo de silencio y paz se alterna con el de violencia. La explicación de este proceso es difícil, y sobre todo en cada caso particular; por lo pronto, habría que tenerlo presente y preguntarnos para qué y por qué se produce. En princpio, fue con el paso del tiempo que algunas situaciones se fueron aclarando, o más bien fueron conocidas o imputadas a ciertos actores sociales.

\section{LOS HOMICIDIOS}

Los homicidios no parecían tener una sola causa. Algunos podían relacionarse entre sí, pero no todos. Un rasgo general los caracterizaba: la venganza, que aparecía como factor central vinculado a móviles de distinta índole. La forma de ejercer la venganza es variada y combinada.
Muchas de las muertes fueron provocadas por arma de fuego, lo que implica violencia interpersonal directa, pero otras lo fueron (o supuestamente) por medio del nagualismo. Este tipo de muerte se imputa a alguien y la consecuencia es la posible provocación de una venganza; se considera asesinato, aunque las pruebas no indiquen violencia directa, sino mediada por la creencia en la existencia de naguales.

La relación de la persona con su nagual es eminentemente social, pues al decir de Villa Rojas el nagualismo se entiende "en su función de controlar las relaciones interpersonales de los miembros de la comunidad" (1963: 243). La violencia puede ser ejercida por uno o varios animales (naguales) sobre otro, causándole la muerte y por ende la muerte de la persona. Cabe señalar que actualmente ésta es una causa frecuente de demanda, tanto por daño como por muerte, ante las autoridades locales.

Los motivos de venganza, llamémosle directa (violencia física) o indirecta (violencia mágico-simbólica, a través del nagualismo), tenían distintos orígenes. La mayoría se derivaban de problemas privados o personales, sin que se llegara a saber con exactitud la historia completa de cada muerte. En buena medida, la privacidad de los hechos se corresponde con su conocimiento público; es decir: la comunidad está informada de los acontecimientos violentos, pero al mismo tiempo guarda una cuidadosa discreción sobre ellos, pues los hechos del pasado, conocidos por todos, se explicarán en el futuro.

El tiempo en que se desencadenan las muertes implica la existencia de diversas causas conflictivas primarias. La información obtenida sobre los tipos de homicidio indica distintos motivos: robo colectivo (1); conflictos por linderos de tierras (1); testigos de homicidios anteriores (2); motivos personales (4); confusión o compañía con la presunta víctima (2); conflictos familiares conocidos (1); nagualismo declarado (2). En estos casos, la mayoría fueron asesinatos con arma de fuego y uno a golpes con palos por varios sujetos. Algunas de estas muertes estaban asociadas entre sí, pero no era el caso de todas.

Aparte de las dos muertes en que la causa señalada fue una venganza por supuesto nagualismo, varios de los homicidios están relacionados con muertes anteriores por imputaciones de la misma naturaleza. El móvil de ho- 
micidio por nagualismo significa que la venganza física ejercida tiene antecedentes por esa causa. En otros casos, el móvil y la acción están unidos; es decir: un homicidio se explica por la muerte de un nagual atacado por otro.

Algunas de estas muertes están vinculadas a más de un motivo; por ejemplo: venganza personal, más conflictos previos por terrenos, más problemas entre vecinos o familiares. Sólo un caso está ligado al móvil de robo; en él participaron varios individuos, e incluso algunos no eran del lugar. Todos los demás casos se asocian a conflictos internos de la comunidad.

De estos homicidios, se sabe que sólo dos fueron denunciados; en ambos casos, por la propia víctima moribunda, quien dió las señas de sus agresores. Ignoro el curso del proceso, pero los presuntos homicidas fueron detenidos por la autoridad local y llevados ante las autoridades del distrito judicial (instancia superior). Los demás crímenes no se aclararon en términos judiciales, pero sí en términos de una deducción comunal, lo cual, evidentemente, no ofrece ningún testimonio de validez jurídica, pero sí la continuación de las venganzas. Tal deducción, sustentada en el mundo mágico de la creencia en los naguales, tiene una lógica que permite imputar culpabilidades con el paso del tiempo y por el comportamiento de los actores sociales; es decir, estas culpabilidades se deducen de los acontecimientos que siguen a los hechos violentos, según la lógica establecida en el mundo de los naguales.

\section{LA LÓGICA VIOLENTA DEL MUNDO DE LOS NAGUALES}

Algunas personas nacen con nagual, pero no todas. Con el tiempo se puede saber quién posee este poder, aunque nadie lo acepte, pues ello implicaría revelar un punto de ataque o debilidad a los posibles enemigos. Frecuentemente se sabe quién era nagual por su forma de morir; es decir, muere porque le "pegaron" a su nagual. Esta muerte necesariamente se adjudica al nagual de alguna persona, lo que implica la intencionalidad del crimen. Ningún nagual muere por casualidad.
Esta concepción de nagualismo comparte las características generales de la creencia en la región; esto es, como un animal-doble de la persona (véase Aguirre Beltrán, 1992); sin embargo, adquiere connotaciones particulares en nuestro caso, en relación con el daño mortal. Nagualismo y brujería se relacionan, pero son dos cosas distintas. Un brujo, por lo general, tiene nagual pero no todos los naguales son brujos. Así, no se requiere de poderes especiales de inicio, sino que éstos se van mostrando por el actuar de las personas.

La creencia en los naguales está muy vinculada al mecanismo social de venganza, la cual incluye el homicidio y daños no mortales. Por este medio la sociedad participa en los procesos vengativos y, se podría decir, agudiza y obliga a ejercer la venganza a sus propios miembros. Una muerte por nagualismo se caracteriza porque es espontánea, sin agresión física visible, ni por arma ni por una enfermedad prolongada. Las huellas de la muerte aparecen en el cuerpo del difunto y en los rastros dejados por su animal. Las huellas en el cuerpo pueden ser moretones, cuello hinchado y sangre cuajada. Asimismo, se encontrará al animal muerto cerca de donde murió la persona o en algún lugar asociado con ella. $\mathrm{Al}$ animal le hacen daño otros naguales. Una persona no puede saber qué animal es el nagual de su enemigo y así hacerle daño, pero el nagual de una persona sí lo puede saber.

Los naguales se comunican entre sí, y siempre habrá alguno que vea lo que pasa en el monte o en un paraje distante, y podrá contarlo a la persona (una vez que ha sido atacada). Así, un nagual moribundo, que tiene como consecuencia el mal estado físico de la persona en el mismo momento, puede comunicarse con la persona y decirle que le está haciendo daño otro nagual. La persona, en su agonía, puede decir quién es el culpable de su mal, y si llega la muerte, se considerará que esa persona fue muerta por nagualismo; al mismo tiempo, quedará abierta la puerta para la venganza. Los naguales quedan, así, como seres vigilantes de la sociedad, evitando el anonimato de la agresión.

La creencia establece que el poder de los naguales no puede traspasar el ámbito territorial del grupo; es decir, un nagual de un pueblo no puede ir a matar a un habitante de otro pueblo. Sin embargo, si alguien considera 
que le están haciendo daño, y no es un nagual, el mal o enfermedad se adjudica a un brujo poderoso de fuera del pueblo y se podrá contrarrestar con la ayuda de otro brujo. Ello indica que nagualismo y brujería no coinciden, aunque se vinculen; es decir, un brujo tendrá que ser nagual fuerte para tener poderes fuertes, pero no todo nagual es un brujo.

Los naguales están presentes en la sociedad de manera anómima, vigilante, protegiendo del daño y evitándolo con su presencia mimetizada. Nadie dirá que es nagual y mucho menos cuál es, pero el tiempo y los acontecimientos lo revelarán. Aunque se llegara a saber, o alguien muy borracho declarase cuál es su animal, nadie lo dirá o lo repetirá en público, pues el hecho de saberlo es convertirse en posible vengador o víctima. Esta descripción del nagualismo la he reconstruido a través de pláticas dispersas, pues hablar del tema resulta muy inquietante.

\section{ALGUNOS ANTECEDENTES HISTÓRICOS}

Otro factor que influye en este panorama de violencia es el contexto histórico. Me refiero no sólo a las historias o genealogías interfamiliares atadas por actos de venganza -que configura en buena medida la violencia local一, sino también al contexto histórico inmediato del pueblo. Los antecedentes más importantes se refieren al conflictivo movimiento agrario de finales de la década de 1970, que dejó varias víctimas indígenas en el enfrentamiento contra algunos de los caciques del lugar y muchas rencillas. Sin embargo, el sistema de venganzas no funciona entre indígenas y mestizos. En raras ocasiones se sabe de la muerte de un mestizo a manos de un indígena. $\mathrm{La}$ violencia entre mestizos es diferente, $y$ cuando un mestizo asesina a un indígena el hecho es acallado o entra en la órbita judicial estatal.

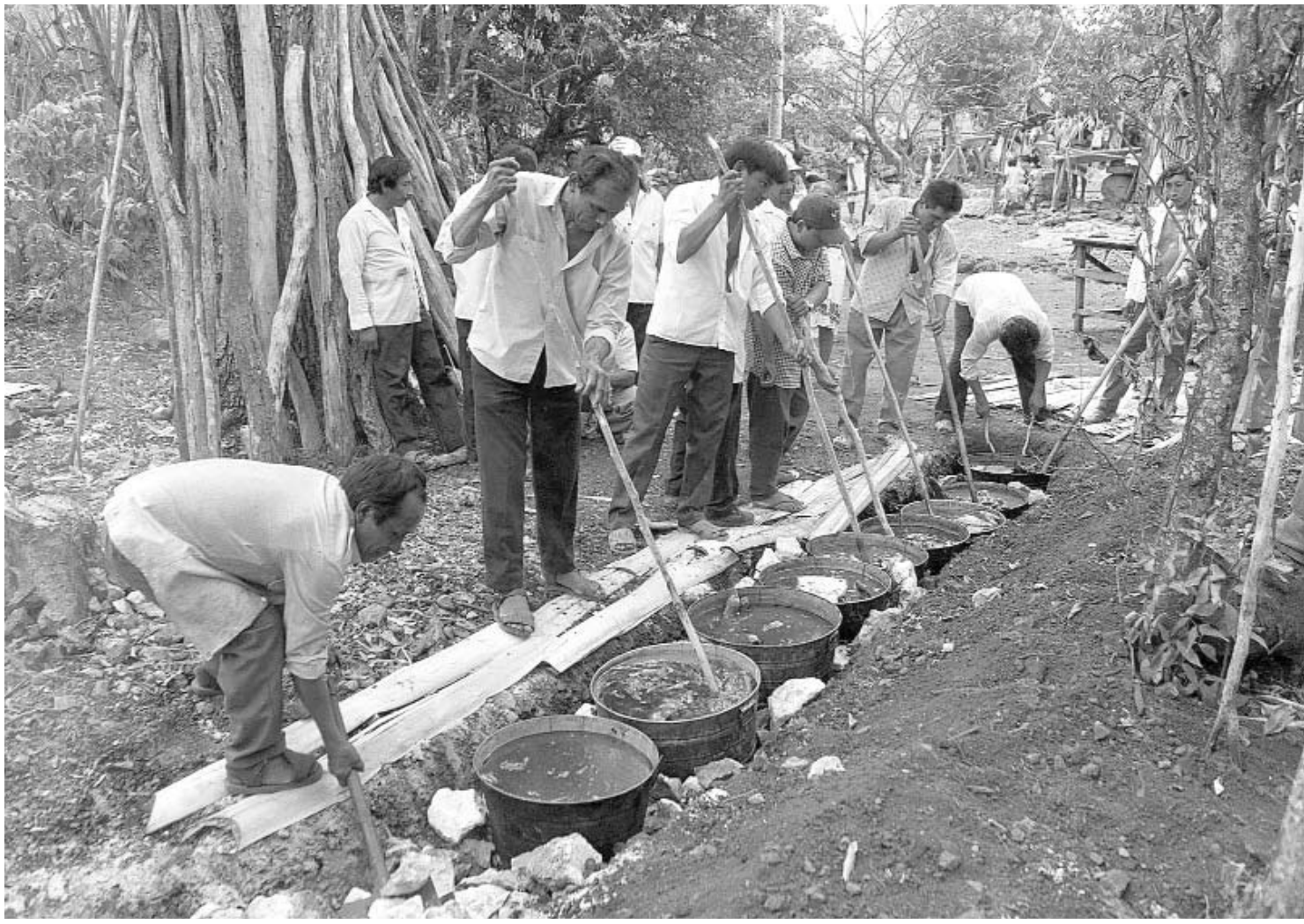

Preparación de "relleno negro", comida obligatoria en cualquier fiesta de los pueblos mayas tradicionales / Christian Rasmussen. 
El antecendente de lucha agraria facilitó el mayor acceso a los cargos municipales por parte de indígenas, incluyendo la presidencia y la sindicatura municipal, en donde recaen las denuncias. El acceso de los indígenas a puestos de poder público hizo posible que el sistema de venganzas y el nagualismo se denunciara ante autoridades. Siendo éstas indígenas no quedan exentas de la lógica comunal que las hace partícipes del efecto de las creencias de nagualismo, y en ese sentido de la complicidad social. Por ello, su acción frente a estos hechos no sólo dificulta el ejercicio de su función en la población indígena, sino también en la canalización de los homicidios hacia las instancias judiciales competentes, donde simplemente una acusación por homicidio bajo la demanda de nagualismo no tipificaría el delito.

Cuando las autoridades eran mestizas, a pesar de la represión hacia este tipo de conductas, era evidente la total desconfianza en su capacidad de impartir justicia en los conflictos entre indígenas, y así las venganzas operaban en la sociedad indígena bajo las reglas establecidas, es decir, en la lógica de la justicia comunal y sin denuncia ante las instancias judiciales locales. Ante autoridades indígenas la situación se modificó, sin que ello evitara que se siguiera reproduciendo la lógica de venganza. En el caso de que la autoridad sea indígena, su acción no es garantía de imparcialidad debido a su involucramiento personal en las redes de conflictos sociales; se produce entonces un mayor conocimiento de los asuntos, pues se conocen las creencias sobre los naguales pero al mismo tiempo la autoridad carece de credibilidad en relación con el cumplimiento de su función de "tercero excluido". Así, se puede inferir que el mecanismo social de venganzas tiene una estructura muy enraizada en la sociedad desde mucho tiempo atrás y que se agudiza en situaciones conflictivas internas.

\section{EL PROCESO DE ADJUDICACIÓN DE CULPABILIDAD}

Aunque los elementos centrales de esta parte del ensayo están tomados de lo que la gente dice de forma conjetural y dispersa, básicamente se trata de una elaboración analítica de factores que no aparecen construidos claramente en el discurso cotidiano de la sociedad.

El mecanismo por medio del cual se conoce socialmente la culpabilidad de un presunto homicida está basado en la sospecha. Que una persona muera, aunque aparentemente haya sido por causas naturales, puede ser imputable al nagualismo, particularmente cuando se encuentran señales interpretables como pruebas; esto es: huellas en el cuerpo de la víctima y/o en algún animal muerto vinculado a ella. Estas supuestas evidencias implican que la persona no murió de muerte natural, sino que alguien la mató.

La sospecha de quién fue el causante comienza a salir a la luz de forma paulatina; aunque en algunos casos se pudiera saber casi inmediatamente por la flagrancia del hecho, nadie lo dirá, pues correría el riesgo de verse involucrado o de anticipar la preparación de la venganza y darle oportunidad de escapar o de "adelantarse" a la persona sospechosa. En este sentido, el camino de la comprobación comienza con el silencio, incluso de la familia de la víctima, con el fin de evitar la idea de que se sospecha de alguien en particular. Luego debe pasar un lapso de espera en el que, de alguna manera, se busca que el culpable muestre las pruebas en una especie de anticipación de su responsabilidad. La espera va determinando los vínculos de la víctima con el presunto culpable: problemas anteriores o conflictos conocidos por la comunidad que pueden datar de muchos años atrás. Lo importante es establecer la enemistad entre las partes. Otra prueba, casi de tipo confesional, es que el sospechoso abandone el pueblo.

El tiempo de espera resulta fundamental para la deducción de quién es el culpable. En una conferencia dirigida a futuros jueces y defensores, ante la pregunta de si el método del psicoanálisis puede ayudar en la investigación judicial para determinar la culpabilidad de un individuo, Sigmund Freud respondió recomendando el desarrollo de "investigaciones durante un cierto número de años", tal y como es el proceso de escucha en el método analítico, pero agregó: "sin que los resultados de las mismas hayan de influir para nada en la decisión final" (Freud, 1906: 1283). Tal respuesta deriva de que en el tratamiento de la neurosis la culpabilidad se asume como una incer- 
tidumbre. De forma similar, en la creencia mágica la prueba de culpa no resulta de un proceso evidente, incluso ni siquiera se tiene la certeza en la prueba testifical o confesional, pues podrían ser inciertas. El consejo de Freud es que no hay manera de saber con certeza la culpabilidad más que por las secuelas que deja en el tiempo, aspecto en que un proceso judicial no puede basarse. Para el pensamiento mágico simbólico el aserto de culpabilidad resulta de un mecanismo semejante. El tiempo, la espera y la anticipación elaboran una cierta certeza subjetiva a partir del comportamiento relacionado con los otros individuos: los posibles culpables. Lacan (1971) ha mostrado este mecanismo de certidumbre anticipada basado en el aserto temporal, por medio del cual un individuo se identifica a sí mismo a la espera y deducción del comportamiento de los otros, anticipándose a identificarse antes que los demás lo hagan. Este mecanismo opera, de forma parecida, en la deducción de la culpabilidad mágica.

En principio, ningún homicidio podrá quedar en el anonimato, dada la comunicación entre naguales y perpeligro, puede comunicarse con su nagual, o el nagual con la persona, para avisar del daño que sufre; pero nadie lo sabe con certeza. Con ello se genera una garantía de que ningún homicidio puede ser ocultado para siempre. La gente confía en que el homicida va a "caer". La prueba final llega cuando se ejecuta la venganza; cuando alguien muere por nagualismo o es asesinado se comprueba, con los antecedentes del caso, que esa persona fue la culpable de una muerte anterior, ligada ahora con el nuevo ejecutor de la venganza. En muchas ocasiones, en el lecho de muerte, el culpable confiesa haber matado a tal o cual persona. Por decirlo de alguna manera, ese proceso se cierra y al mismo tiempo se abre el siguiente, evidentemente con la sospecha de quién es el presunto vengador, esto es, alguien asociado a la primera muerte. Este proceso parece no tener término, a excepción de que una de las partes implicadas abandone la comunidad.

En estos casos nadie se presenta a testificar ante autoridades, pues ello lo implicaría y se haría sujeto de una posible venganza. La persecución de oficio por parte de las autoridades locales no llega a canalizarse a las autori-

dades jurisdiccionales competentes, pues, como se dijo, simplemente la causa de nagualismo, sin más evidencia que la sospecha social, sería improcedente ante el sistema judicial. La única manera en que la autoridad local puede actuar y canalizar la sanción judicial es cuando la propia víctima alcanza a testificar y denunciar a sus agresores. Pero en caso de que la víctima no esté en peligro de muerte, sino que sólo haya sufrido un atentado menor, puede no querer declarar y se reserva el conocimiento de los hechos para actuar privadamente. La actuación de las autoridades locales puede sancionar, en algunas ocasiones, las denuncias de daños por nagualismo previo a un desenlace fatal.

El silencio, la sospecha que anuda los vínculos entre las partes en conflicto y la espera o desenlace llegan, en todos los casos, a concluir en la culpabilidad de alguien. Y si la víctima no ha sido vengada, la sociedad ejercerá presión para que los allegados a ella hagan algo, de forma que esa muerte no quede en el olvido.

\section{REFLEXIONES FINALES}

1. En el caso estudiado se observan tres tipos de imputación de homicidio: a) directo, de persona a persona; b) entre naguales, de nagual a nagual, con el efecto de culpabilidad y de victimización de personas; c) estructura combinada - la más frecuente- encadenada en el tiempo de las venganzas, entre asesinatos directos e indirectos; es decir que a la muerte de alguien por nagualismo puede suceder una venganza directa, física, por arma, entre personas.

2. Las cadenas de venganzas concluyen solamente por el abandono del pueblo, sea del posible vengador que renuncie a vengarse por no poder resistir la presión social o por la huida de la potencial víctima, con lo cual comprueba a los ojos de la sociedad su posición en el conflicto. El proceso de venganza se reiniciará al regreso de cualquiera de las partes, y no se da por concluido aunque pase largo tiempo.

3. La sociedad adjudica las culpabilidades por un proceso de esperas temporales, basadas en las sospechas derivadas de los antecendentes de enemistad de las partes. 
La culpabilidad es imputada al surgir la muerte esperada, como especie de confesión de la agresión previa, que puede distar varios años o cumplirse por parientes de la generación siguiente a la de los involucrados inicialmente. Esto no significa que todas las muertes sean vengadas o aclaradas, pero sí prueba que la venganza producida aclara un crimen anterior. El tiempo de espera es importante, pues una persona puede haber tenido varios enemigos y es entonces necesario esperar para saber quién de ellos la victimó.

4. El sistema funciona como una forma de control social, de justicia a manos de la propia sociedad (sistema de venganzas de sangre dentro de una lógica basada en la reciprocidad del daño), y en donde se pretende que el ilícito nunca quede impune ni en el anonimato. Tarde o temprano todo homicidio tendrá su culpable confeso, imputado o evidenciado a los ojos de la sociedad. Se puede decir que se trata de un sistema de reciprocidad en el daño social que, ante la falta de una autoridad legitimada en el papel del tercero excluído, el juzgador imparcial, hace obligatorio para los miembros del grupo el entrar en el circuito de adjudicación de la culpabilidad y de la posible venganza.

5. En muchos casos, los naguales representan a personas que por diversos motivos muestran su agresividad social; el tener nagual es una selección social que imprime la sociedad a ciertos individuos con características especiales, difíciles de precisar, aunque creo que vinculadas a conductas consideradas extrañas al interior de la cultura y, sobre todo, enclavadas en cadenas de hechos anteriores. Los posibles naguales canalizan el desorden social, al mismo tiempo que la sociedad imprime sus reglas de control.

6. El silencio y la sospecha son los medios de prueba empleados por el conjunto social para "deducir" los hechos e imputar responsabilidades. Cabe señalar que, si bien es difícil para un observador externo encontrar las pruebas concluyentes de una responsabilidad delictuosa, por lo general, si no es que en la totalidad de los casos, la sociedad no se equivoca ni actúa parcialmente al esclarecer o explicarse el crimen. No se equivoca porque la prueba o el veredicto de la sociedad es dado hasta el final del seguimiento del caso; es decir,

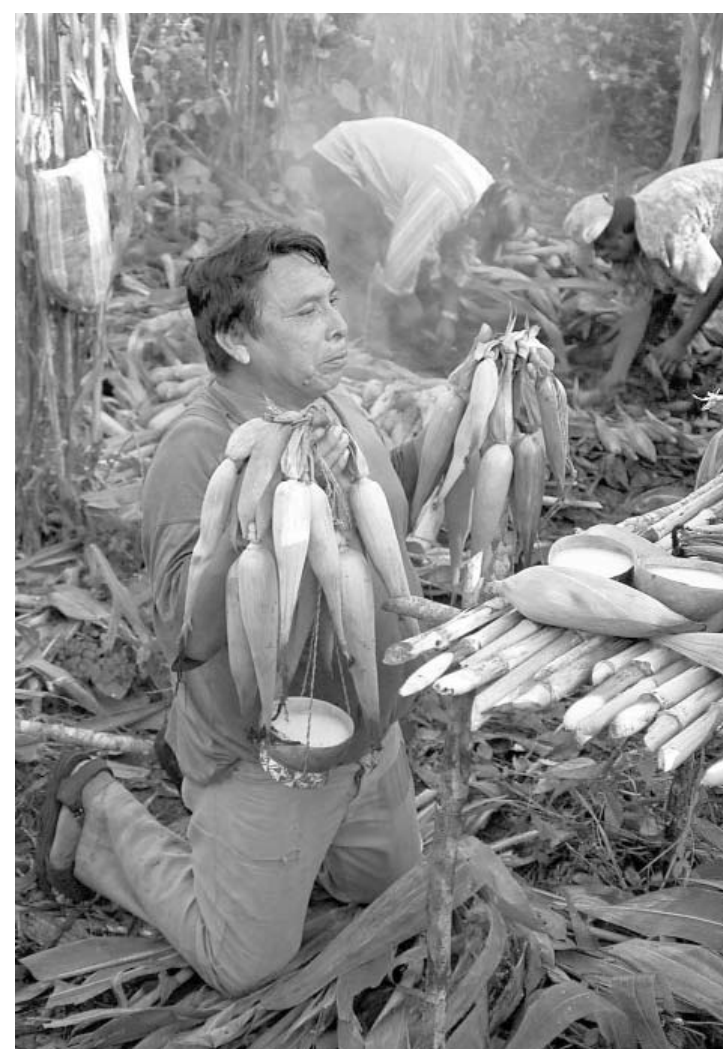

Don Teodoro Canul ofrenda en la milpa la primera cosecha de maíz / Christian Rasmussen.

cuando acontece la muerte del culpable a manos de un descendiente del ofendido anterior, aunque pasen muchos años. Cabe señalar el cuidado general que tiene el conjunto social en imputar responsabilidades, no sólo por el efecto del miedo de ser receptor de una deuda vengativa, sino también por la obligación social de dar castigo al culpable y ejercer un control social y una justicia interna. Recurrir a la venganza puede ser también la muestra de una injusticia manifiesta que debe ser reparada.

7. La violencia desencadenada por rachas, a las que siguen tiempos de aparente calma y paz, no es arbitraria ni ocasional, ni derivada de una agresividad espontánea (producida por efectos de riñas y consumo de alcohol), sino la forma en que la sociedad se protege de los comportamientos antisociales, sobre todo ante el hecho 
de carecer de autoridad legitimada en el sistema judicial estatal. Es decir, que si se quisiera dar una explicación de estas reglas para controlar la violencia, para regularla, se podría decir que la razón principal se debe a la falta de legitimidad de la autoridad, de donde la sociedad en su conjunto asume las funciones de vigilar y sancionar. En este sentido, esta forma de violencia — que sin duda lo es — resulta diferente de la violencia caracterizada por la impunidad.

8. Los hechos que inicialmente no están conectados a una venganza familiar, sino que surgen de una actitud violenta nueva (como el homicidio motivado por el robo, por efectos del alcohol, o por otra causa sin antecedentes de enemistad) entran en el circuito de la venganza. De esta forma, la sociedad busca una disuación a la violencia — porque nadie escaparía a los efectos de ella - antes que su aumento indiscriminado. En este sentido, y a pesar de las rachas de violencia-paz, la sociedad controla el índice de violencia, diferenciando también la originada entre los miembros del mismo grupo de la originada por otros factores, gualismo, opera un mecanismo para ejercer un control social sobre ella. Esta lógica, lejos de dar una justificación cultural al ejercicio de la violencia, revela la importancia de los sistemas culturales de control social para generar mecanismos de restricción de hechos violentos.

\section{Bibliografía}

Aguirre Beltrán, Gonzalo, 1988 (1958), Cuijla. Esbozo etnográfico de un pueblo negro. Obra antropológica, vol. VII, FCE, México.

—_, 1992 (1963), Medicina y magia. Obra antropológica, vol. VIII, FCE, México.

Báez-Jorge, F. , 1998, Entre los naguales y los santos, Universidad Veracruzana, Veracruz.

Evans-Pritchard, E. E., 1976, Brujería, magia y oráculos entre los azande, Anagrama, Barcelona.

Flanet, Veronique, 1989, Viviré si Dios quiere, Instituto Nacional Indigenista y Consejo Nacional para la Cultura y las Artes, México.

Foster, George M., 1944, "Nagualism in Mexico and Guatemala", Acta Americana.

Freud, Sigmund, 1906, "El psicoanálisis y el diagnóstico de los hechos en los procedimientos judiciales", Obras completas, t. II., 3a. ed., trad. de Luis López-Ballesteros, Biblioteca Nueva, Madrid.

Holland, William R., 1961, "El tonalismo y el nagualismo entre los tzotziles”, Estudios de Cultura Maya, México.

Lacan, Jacques, 1971, "El tiempo lógico y el aserto de certidumbre anticipada. Un nuevo sofisma”, Escritos, t. I, Siglo XXI Editores, 2a. ed. en español, México.

Malinowski, Bronislaw, 1982, Crimen y costumbre en la sociedad salvaje, Ariel, Barcelona.

Ruvalcaba Mercado, Jesús, 1991, Sociedad y violencia. Extracción y concentración de excedentes en la Huasteca, Cuadernos de la Casa Chata, CIESAS, México.

Thomas, Norman D., 1974, Envidia, brujería y organización ceremonial. Un pueblo zoque, Sep-Setentas, núm. 166, México.

Sanders, Todd, 2003, "Reconsidering Witchcraft: Postcolonial Africa and Analytic (Un)Certainties", American Anthropologist, vol. 105, núm. 2, junio, pp. 338-352.

Villa Rojas, Alfonso, 1947, "Kinship and Nagualism in a Tzeltal Community, Southeastern México", American Anthropologist, vol. 49, pp. 578-587.

Para terminar, y a partir de la lógica simbólica que rodea la representación de la violencia en la sociedad amuzga, se puede decir que cuando es mediada a través del na-
_, 1963, "El nagualismo como recurso de control social entre los grupos mayances de Chiapas, México", Estudios de Cultura Maya, vol. 3, pp. 243-260. 